\title{
Spy in the Huddle: Expression of Anthropomorphized Subjects in the Wildlife Documentary
}

\author{
Xuefeng Zhao, Xianyao Zou \\ College of Culture, Creative and Communication, Zhejiang Normal University, Jinhua, China \\ Email: 201620200844@zjnu.edu.cn, zxy888@zjnu.edu.cn
}

How to cite this paper: Zhao, X.F. and Zou, X.Y. (2017) Spy in the Huddle: Expression of Anthropomorphized Subjects in the Wildlife Documentary. Open Access Library Journal, 4: e3788.

https://doi.org/10.4236/oalib.1103788

Received: June 29, 2017

Accepted: July 15, 2017

Published: July 18, 2017

Copyright $\odot 2017$ by authors and Open Access Library Inc.

This work is licensed under the Creative Commons Attribution International License (CC BY 4.0).

http://creativecommons.org/licenses/by/4.0/

\section{(c) (i) Open Access}

\begin{abstract}
This article explores the narrative strategy of Anthropomorphism of penguins. Spy in the huddle, the BBC wildlife documentary miniseries launched in 2013 which avail itself of anthropomorphized subjects to bring the series with entertaining and intriguing. It takes the rules and moral norms of human society to explain the behavior of animals by intentional erasure of the animality of subjects depicted with the fictitious personalities and attempts to seek out a relation of affinity and balance between animals and human beings. With the resourceful application of the anthropomorphic strategy, much wider significance based on natural aesthetics was cognizant of by a mass audience.
\end{abstract}

\section{Subject Areas}

Art, Journalism and Communication

\section{Keywords}

Spy in the Huddle, Wildlife Documentary, Anthropomorphism, BBC

\section{Introduction}

The BBC documentary series Penguins. Spy in the Huddle (2013) directed by John Downer conducted a track record of different types of penguins in three different regions for nearly a year. In order to make penguins not to be disturbed by shooting and to perform their most natural states, the documentary crews prepared a variety of Camera devices disguised as penguins, penguin eggs, and even stones undercover in the penguin groups. Approximately seventeen machines and fifty cameras kept track of these penguins day and night. It portrayed intentionally the animal behaviors as human ways on the basis of moral rules of 
human society, which promoted the intercourse between the animals and audiences that alienated from the natural ecosystem for ages. And basically it was not rarely seen in the existing wildlife documentaries with that strategy.

This new rhetoric strategy changed the way of production of wildlife documentaries even found themselves with a new marketplace. In general, the documentary making use of anthropomorphized animals does not represent objective reality which betrays the most essential characteristic of documentary, owing to the simple fact that animals do not have human natures in a real sense. But can the new rhetoric method in the wildlife genre that combined high levels of factitious editing and seemingly objective narratives offer constructive and truer images of the routine lives of individual animals in the wild? The article takes Penguins. Spy in the Huddle as own case to looking for the answer and explore the substantial implications in terms of its philosophical connotation, aesthetic significance and commercial value with concrete analysis of application of anthropomorphic narrative in the wildlife documentaries.

By presenting the process of universalization of anthropomorphic strategy and a conceptual framework of evolvement of wildlife documentaries over the course of the past few years, the article tries to reveal some obscure changes of modes of documentary production and conclude the legality and rationality of the rhetoric method of anthropomorphism with example of Penguins: Spy in the Huddle.

\section{The Development and Evolution of Wildlife Documentaries}

According to the records, the earliest wildlife documentary may be filmed in the late $19^{\text {th }}$ century. Owing to the restrictions of photography technology, this type of documentaries was all recorded in the zoo at that moment. In 1989, the German pioneer filmmakers Oskar Messter produced four short documentaries for the animals which are On the Chicken Farm, the Monkey and Trainer, Lion Cubs of Berlin Zoo, and Tamed Indian elephant. From the very beginning the animal subjects did not represent any human characteristics in the documentaries.

In 1907, the British film for animals In Birdland was filmed. And then The Private Life of Gannet won the Oscar Award for the Best Cinematography in 1937. In 1954, The Zoo Quest was for the first time to allow the host work in the field, which led to a real sense of the wildlife documentary. In 1979, Life on Earth produced by David Attenborough broadcast on BBC, which set a benchmark of quality for the wildlife documentaries and exerted a great impact on the generations of documentary film-makers beneath him. In 1990, The Trials of Life: A Natural History of Behaviour was also completed and presented by David Attenborough focusing on the animal behaviors by different stages of life after the success of Life on Earth. The animal images projected enlightened audience on the greatness of lives of animals that made a proposal of regarding them on a equal footing with sympathy and compassion. From then on the animals in the wildlife documentaries were not just a tool to spread out the cruelty of nature. 
In 1999, Walking with Dinosaurs, a six-part documentary television series, was aired on the BBC with large CGI elements in terms of essential creatures imagery for the dynamic visual effects, which blurred the boundary of fiction and nonfiction. In 2001, The Blue Planet, a British nature documentary series, first transmitted on $\mathrm{BBC} 1$ and narrated by David Attenborough won the Oscar Award for the Best Cinematography, Best Sound, and Best Documentary Feature. In 2005, a French feature-length nature documentary March of the Penguins directed and co-written by Luc Jacquet exhibited the magnificent scenery of Antarctic continent and was the first time endowing penguins with human features by means of the anthropomorphic strategy. In 2009, a documentary film The Cove directed by Louie Psihoyos which brought the mass dolphin killing practices in Japan to the public. The cruelty and ruthlessness of human beings dealing with other species on earth manifested the arrogance of human race under the value of anthropocentrism and exposed the extreme wrongness that treating animals as if they had no feelings.

In 2013, the new series of BBC Wildlife Specials Penguins: Spy in the Huddle have been broadcast on BBC One. The anthropomorphic society of penguins aroused resonance with audience. Along with the development and evolution of wildlife documentaries, the animals as impersonally observed objects in image texts changed into the main subjects with abstract humanity. The utilization of anthropomorphic strategy promoted audience to better understand the behaviors of the animals, which help human coordinate and deal with the relationship between human beings and nature or even improves the consciousness to protect fragile wildlife.

\section{Tracking the Strategy: Anthropomorphic Images of the Penguins}

The animals, as individuals on earth, have the equal rights to live as human beings, in spite of the value of the existence of animals as the subjects of the wildlife image works has been ignored by humans for a long time. Several filmmakers exploited the cruel laws of nature to stimulate the eyes of viewers with dramatic attack scenes involving predators and the cruelty of the hunting practices, which led to a relation of alienation and indifference in human beings and animals. Notwithstanding the anthropomorphic Images can increase the amusement for the documentary itself, the essence of documentary is to perform the real. Apparently animals do not have the human feelings as humans. The customary regulations of human society, as a device to interpret animal behaviors, supports to set up a fictional image text dependent on the psychological hints by the metaphorical sequences and voice-over narration.

The functions of the documentary require its responsibility to present reality. But the images of anthropomorphized penguins, to a certain extent, did not perform objective and realistic acts. Or, from another perspective, the image texts processed won't present a completely reality. As an image work to the market, anthropomorphized animals could enrich the entertainment of the do- 
cumentary like doing a wildlife docusoap and also promote the public to easily pick up the philosophical significance under the amusing cosmetic. In a documentary, there can never be completely true to facts. The appearance of being true of documentary gives audience artificial authenticity, credibility and believability, which means the anthropomorphic rhetoric of wildlife documentary is legal and rational. "In other words, wildlife maker should focus on conveying an accurate portrait of wild animals and the issues they face, rather than on the precise level of construction involved "(Richards, 2014: 332) [1].

To depict the behaviors of penguins, human-specific phrases and expressions have been widely used, which drove to build up the psychological connection between the penguins and audience. For instance, when the snowstorm hit, a good friend of the mother penguin came to give a "comfort" for her lost because of the tragic death of her chick. Through the suggestive narration and symbolic footage, the audience will be affected by the fictitious grief of the mother penguin. Another example for the anthropomorphic description of the penguins is the event of the courtship behavior between Humboldt penguins. As the female Humboldt penguin late return, a male Humboldt penguin even publicly cheated on her with a "penguin spy". At that moment human relationships were applied onto these penguins. In the documentary series, many of emotional words and phrases for humans were used to animals, such as jealousy, comfort, loneliness, abandonment, sympathy, etc, and "The social construction of nature is necessarily an element of the social evolution of society" [2] (Eder, 1996: 8).

At present, this technique has been widely used in wildlife documentaries, which not only increased attractiveness of the documentary itself but also built up the philosophical significance from an ecological origin, just because it's the most infectious expressions and tools to dealing with the relationship between human race and nature.

\section{Conclusion: Humans, Animals and Nature}

The ecological criticism rising in the 90s advocates to understand the relationship between natural environment and human civilization to build a harmonious unity of human beings and nature. A concept of ecological criticism combining literature and ecology has been come up with (Wang, 2011) [3]. As the prosperity of the humanism in the last century, several ideological liberators brought a branch of environmental philosophies including environmental aesthetics, ecofeminism, environmental hermeneutics, environmental ethics, and environmental theology forward, which made the realization from "humancenter theory" to eco-centrism.

As this analysis has shown, the wildlife documentary penguins. Spy in the huddle utilized anthropomorphic strategy to deconstruct a simple binary structure and strained relationship between human beings and animals. With the application of this narrative method, the documentary no longer presented a story of predators and prey but passed out an idea which is to maintain harmony with nature and respect the animals. Also the strategy in wildlife documentaries em- 
bodied the theory of natural aesthetics which explained all the lives of nature as beautiful (Carlson, 2002) by a deliberate erasure of the animality to humanize them with human feelings and behaviors [4].

Throughout the evolution and development of wildlife documentaries, the anthropomorphic strategy wasn't rare to see in recent image works. Furthermore it has its own philosophical significance from ecology and economic value like attracting audience or improving TV ratings. This article demonstrated the legality and rationality of the narrative strategy of anthropomorphism in wildlife documentary and illustrated the significance of this technique.

\section{Acknowledgements}

Here and now, I'd like to appreciate my colleges which provided me with many useful academic materials and show my deepest gratitude to my supervisor, Mr. Zou, who has walked me through all the stages of the writing. My sincere appreciation also goes to my best friends for their impressive encouragements and supports.

\section{References}

[1] Richards, M. (2014) The Wildlife Docusoap: A New Ethical Practice for Wildlife Documentary? Television \& New Media, 15, 321-335. https://doi.org/10.1177/1527476412465656

[2] Eder, K. (1996) The Social Construction of Nature. Sage, London.

[3] Wang, N. (2011) Ecological Literature in Europe and America. Peking University Press, Beijing.

[4] Carlson, A. (2002) Aesthetics and the Environment: The Appreciation of Nature, Art and Architecture. Routledge, London.

Open Access Library

Submit or recommend next manuscript to OALib Journal and we will provide best service for you:

- Publication frequency: Monthly

- 9 subject areas of science, technology and medicine

- Fair and rigorous peer-review system

- Fast publication process

- Article promotion in various social networking sites (LinkedIn, Facebook, Twitter, etc.)

- Maximum dissemination of your research work

Submit Your Paper Online: Click Here to Submit

Or Contact service@oalib.com 